\title{
COBALT-FREE NICKEL-BASE WROUGHT SUPERALLOYS
}

\author{
E. P. Whelan \\ C1imax Mo1ybdenum Company of Michigan \\ Ann Arbor, Michigan
}

A study has been made of the influence of $C, C r, C O, M O, W$, $T a, A Z, M n, S i$ and $Y$ on the high temperature oxidation resistance of a group of experimental nickel-base superalloys.

Oxidation was performed in flowing air at $1095 \mathrm{C}(2000 \mathrm{~F})$ with intermittent cycling to room temperature. Al additions increased resistance to oxide spaziing, and $y$ additions limited both total mass gain and oxide spalzing. Mo and $W$ additions improved resistance to both mass gain and oxide spalling. Synergism between $S i$ and each of the elements $T a, Y$ and $A Z$ promoted oxide spaziing. Co was not essential for adequate oxidation resistance. Strese mpture properties similar to those of cobalt-base Haynes AlZoy 188 and of Inconel 617 $(12.5 \% \mathrm{Co})$ at $870 \mathrm{C}(1600 \mathrm{~F})$ and $1095 \mathrm{C}(2000 \mathrm{~F})$ were achieved with a cobalt-free alzoy.

\section{INTRODUCTION}

The current restricted supply and high cost of cobalt has led to an increased interest in the development of cobalt-free superalloys. No cobalt-free wrought solid solution strengthened superalloy with properties equivalent to those of cobaltbase Haynes Alloy 188 (1) or Inconel 617 (2) containing 12.5\% $\mathrm{Co}$, is currently available. The present study was directed towards the development of such an alloy and, accordingly, has evaluated the high temperature oxidation resistance, and to a more limjted extent, the stress-rupture properties, of a group of experimental nickel-base alloys.

\section{EXPERTMENTAL PROCEDURES}

The nominal compositions of the alloys evaluated in this 
study are shown in Table 1. The alloys in Group A represent a $1 / 4$ replicate of a $2^{6}$ factorial design, those in Group B represent a $1 / 2$ replicate of a $2^{5}$ factorial design, and those in Group C represent a $1 / 2$ replicate of a $2^{4}$ factorial design. These designs provide information on the main effects and twoelement interaction effects, either separately or in combination, for the elements varied.

The alloys in Groups $A, B$, and $C$ were prepared from 100$250 \mathrm{~g}$ lots of blended elemental powders that were arc-melted into small ingots in an argon atmosphere. Groups $A$ and $B$ ingots were homogenized at $1260 \mathrm{C}(2300 \mathrm{~F})$, and Group C ingots at $1230 \mathrm{C}(2250 \mathrm{~F})$, for 8 hours in hydrogen. Group A ingots were forged at $1150 \mathrm{C}(2100 \mathrm{~F})$ to a thickness of $5 \mathrm{~mm}(0.2 \mathrm{in.})$, Group B alloys were studied in the homogenized condition and Group C alloys were loo rulled al $1205 \mathrm{C}(2200 \mathrm{~F})$ to $1.5 \mathrm{~mm}$

Table 1 Nominal Alloy Compositions (wt \%)

\begin{tabular}{|c|c|c|c|c|c|c|c|c|c|c|c|c|c|}
\hline Alloy & c & 的 & $5 i$ & $\mathrm{Cr}$ & $\mathrm{NI}$ & $\mathrm{Co}$ & Mo & $\mathrm{W}$ & $\mathrm{Ta}$ & A1 & $Y$ & B & $\mathrm{Zr}$ \\
\hline$A-1$ & 0.1 & - & - & 20 & $\mathrm{BaI}$ & 4 & 8 & 2 & 2 & 1 & - & 0.01 & 0.08 \\
\hline & 0.2 & - & - & 20 & $\mathrm{Bal}$ & 4 & 8 & 6 & 2 & 1 & - & 0.01 & 0.08 \\
\hline 3 & 0.1 & - & - & 25 & $\mathrm{Bal}$ & 4 & 8 & 6 & 6 & 1 & - & 0.01 & 0.08 \\
\hline 4 & 0.2 & - & - & 25 & Bal & 4 & 8 & 2 & 6 & 1 & - & 0.01 & 0.08 \\
\hline 5 & 0.1 & - & - & 20 & Bal & 10 & 8 & 6 & 6 & 1 & - & 0.01 & 0.08 \\
\hline 6 & 0.2 & - & - & 20 & $\mathrm{Bad}$ & 10 & 8 & 2 & 6 & 1 & - & 0.01 & 0.08 \\
\hline 7 & 0.1 & - & - & 25 & $\mathrm{Ba} 1$ & 10 & 8 & 2 & 2 & 1 & - & 0.01 & 0.08 \\
\hline 8 & 0.2 & - & - & 25 & BaI & 10 & 8 & 6 & 2 & 1 & - & 0.01 & 0.08 \\
\hline 2 & 0.1 & - & - & 20 & Bel & 4 & 12 & 2 & $G$ & 1 & - & 0.01 & 0.08 \\
\hline 10 & 0.2 & * & - & 20 & $\mathrm{Ba} 1$ & 4 & 12 & 6 & 6 & 1 & - & 0.01 & 0.08 \\
\hline 11 & 0.1 & - & - & 25 & $\mathrm{Ba} 1$ & 4 & 12 & 6 & 2 & 1 & - & 0.01 & 0.08 \\
\hline 12 & 0.2 & - & - & 25 & $\mathrm{Bal}$ & 4 & 12 & 2 & 2 & 1 & - & 0.01 & 0.08 \\
\hline 13 & 0.1 & - & - & 20 & Bal & 10 & 12 & 6 & 2 & 1 & - & 0.01 & 0.08 \\
\hline 14 & 0.2 & - & - & 20 & $\mathrm{Bal}$ & 10 & 12 & 2 & 2 & 1 & - & 0.01 & 0.08 \\
\hline 15 & 0.1 & - & - & 25 & Bat & 10 & 12 & 2 & 5 & 1 & - & 0.01 & 0.08 \\
\hline 16 & 0.2 & - & - & 25 & $\mathrm{BaI}$ & 10 & 12 & 6 & 6 & 1 & - & 0.01 & 0.08 \\
\hline$B-1$ & 0.1 & - & - & 20 & $\mathrm{Ba} 1$ & 4 & 8 & 6 & 2 & - & - & 0.01 & 0.08 \\
\hline 2 & 0.1 & 0.5 & - & 20 & $\mathrm{Ba} 1$ & 4 & 8 & 6 & 2 & 1 & - & 0.01 & 0.08 \\
\hline 3 & 0.1 & - & - & 20 & $\mathrm{BaI}$ & 4 & 8 & 6 & 5 & I & - & 0.01 & 0.08 \\
\hline 4 & 0.1 & 0.5 & - & 20 & $\mathrm{Bal}$ & 4 & 8 & 6 & 6 & - & - & 0.01 & 0.08 \\
\hline 5 & 0.1 & - & 0.5 & 20 & $\mathrm{Bal}$ & 4 & 8 & 6 & 2 & 1 & - & 0.01 & 0.08 \\
\hline 6 & 0.1 & 0.5 & 0.5 & 20 & $B \backsim 1$ & 4 & 8 & 6 & 2 & & & 0.01 & 0.08 \\
\hline 7 & 0.1 & - & 0.5 & 20 & $\mathrm{Ba} 1$ & 4 & 8 & 6 & 6 & - & - & 0.01 & 0.08 \\
\hline 8 & 0.1 & 0.5 & 0.5 & 20 & Bal & 4 & 8 & 6 & 6 & 1 & - & 0.01 & 0.08 \\
\hline 9 & 0.1 & - & - & 20 & $\mathrm{Ba1}$ & 4 & 8 & 6 & 2 & 1 & 0.1 & 0.01 & 0.08 \\
\hline 10 & 0.1 & 0.5 & - & 20 & $\mathrm{Ba} 1$ & 4 & 8 & 6 & 2 & - & 0.1 & 0.01 & 0.08 \\
\hline 11 & 0.1 & - & - & 20 & $\mathrm{Ba} 1$. & 4 & 8 & 6 & 6 & - & 0.1 & 0.01 & 0.08 \\
\hline 12 & 0.1 & 0.5 & - & 20 & $\mathrm{Bal}$ & 4 & 8 & 6 & 6 & 1 & 0.1 & 0.01 & 0.08 \\
\hline 13 & 0.1 & - & 0.5 & 20 & $\mathrm{BaI}$ & 4 & 8 & 6 & 2 & - & 0.1 & 0.01 & 0.08 \\
\hline 14 & 0.1 & 0.5 & 0.5 & 20 & $\mathrm{Bal}$ & 4 & 8 & 6 & 2 & 1. & 0.1 & 0.01 & 0.08 \\
\hline 15 & 0.1 & - & 0.5 & 20 & Bal & 4 & 8 & 6 & 6 & 1 & 0.1 & 0.01 & 0.08 \\
\hline 16 & $\begin{array}{l}0.1 \\
0.1 \\
\end{array}$ & 0.5 & 0.5 & 20 & Bal & 4 & 8 & 6 & 5 & - & 0.1 & 0.01 & 0.08 \\
\hline$c-1$ & 0.05 & 0.5 & - & 20 & Bal & 8 & 4 & 6 & 6 & 2 & 0.2 & 0.01 & 0.08 \\
\hline & 0.08 & 0.5 & - & 20 & $\mathrm{~B} a 1$ & 8 & 4 & 6 & 9 & 2 & 0.2 & 0.01 & 0.08 \\
\hline 3 & 0.05 & 0.5 & - & 20 & $\mathrm{Bal}$ & 8 & 8 & 6 & 9 & 2. & 10.2 & 0.01 & 0.08 \\
\hline 4 & 0.08 & 0.5 & - & 20 & $\mathrm{Bal}$ & 8 & 8 & 6 & 6 & 2 & 0.2 & 0.01 & 0.08 \\
\hline 5 & 0.05 & 0.5 & - & 20 & $\mathrm{Bal}$ & 8 & 4 & 9 & 9 & 2 & 0.2 & 0.01 & 0.08 \\
\hline 6 & 0.08 & 0.5 & - & 20 & Bal & 8 & 4 & 9 & 6 & 2 & 0.2 & 0.01 & 0.08 \\
\hline 7 & 0.05 & 0.5 & - & 20 & $\mathrm{Ba} 1$ & 8 & 8 & 9 & 6 & 2 & 0.2 & 0.01 & 0.08 \\
\hline 8 & 0.08 & 0.5 & - & 20 & $\mathrm{Ba} 1$ & 8 & 8 & 9 & 9 & 2 & 0.2 & 0.01 & 0.08 \\
\hline$D^{\alpha}-1$ & 0.08 & 0.5 & 0.1 & 20 & \begin{tabular}{|l}
$\mathrm{Bal}$ \\
\end{tabular} & - & 9 & 9 & 3 & $\bar{I}$ & 0.05 & 0.005 & 10.05 \\
\hline 2 & 0.05 & 0.5 & 0.1 & 20 & $\mathrm{BaI}$ & - & 3 & 5 & 2 & 1 & 0.05 & 0.005 & 0.05 \\
\hline $\begin{array}{c}\text { Inconel } \\
517^{b}\end{array}$ & 0.08 & 0.1 & 0.2 & 20.4 & \begin{tabular}{|l}
$\mathrm{Ba} 1$ \\
\end{tabular} & 11.5 & 8.4 & 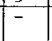 & -0 & 0.8 & - & - & - \\
\hline $\begin{array}{l}\text { Haynes } \\
\text { Alloy } 188^{\mathrm{C}}\end{array}$ & 0.10 & 0.7 & 0.4 & 22.9 & 22.4 & $\mathrm{BaI}$ & - & 14.8 & - & - & - & - & - \\
\hline
\end{tabular}

cHaynes Alloy 188: Heat No. $1880-4-1698$ (containing 1.2Fe, 0.07La) 
(0.06 in.) thick sheet. The Group $\mathrm{D}$ alloys were vacuum melted and cast as $30 \mathrm{~kg}$ heats, extruded at $1150 \mathrm{C}(2100 \mathrm{~F})$ with an extrusion ratio of 4 and then hot rolled at $1205 \mathrm{C}(2200 \mathrm{~F}$ ) to $1.5 \mathrm{~mm}$ (0.06 in.) thick sheet. Sheet samples of similar thickness from commercial heats of Inconel 617 and Haynes Alloy 188 were used in the oxidation studies for reference purposes, and the compositions of these heats are appended to Table 1. Specimens for oxidation studies were polished through 600 grit paper, cleaned and weighed, then oxidized in flowing air for up to 420 hours at $1059 \mathrm{C}(2000 \mathrm{~F})$, using a flow rate of $100 \mathrm{~cm}^{3} /$ sec. Specimens were cooled to room temperature at regular intervals to promote oxide spalling and to permit weighing. Mass gain and mass of spalled oxide were measured at each weighing.

\section{RESULTS AND DISCUSSION}

\section{Group A Alloys}

Oxjdation. The specific mass changes that occurred during the oxidation of the Group A alloys were recorded. Duplicate specimens of Alloys $A-9$ and $A-12$ were exposed and indicated acceptable reproducibility for the test. The total mass changes for all the Group A alloys were greater than those exhibited by Incone1 617 and Haynes Alloy 188 indicating the necessity for compositional modifications to the experimental alloys.

The identity of elements that were most effective in contributing to the obscrved oxidation bchovior was determined from statistical analysis (3) of the mass gain and mass loss data at the end of the oxidation exposure. Based on previous laboratory experience, standard deviations of $\pm 10 \%$ of the mean mass gain and of $\pm 1 \mathrm{mg} \mathrm{cm}^{-2}$ for the spalled oxide data were considered appropriate in identifying mean squares that were significant at a $90 \%$ level of confidence. The elements thus identified as influencing the oxidation resistance of the Group A alloys after 420 hours of exposure are listed in Table 2 . The tabulated coefficient associated with each element indicates the magnitude of the effect on both mass gain and oxide spal1ing, in $\mathrm{mg} \mathrm{cm} \mathrm{cm}^{-2}$, caused by changing that element from its lower to its higher level. A negative sign associated with a coefficient indicates that mass gain or spalled oxide is decreased by the change in composition, which is equivalent to an increase in oxidation resistance.

Table 2 indicates that oxidation resistance in the Group A range of compositions is increased by the increase in Mo and $W$ contents and is decreased by the increase in Ta content. The mass of oxide spalled is decreased by the $W$ and Co additions 
Table 2 Group A Coetticients

\begin{tabular}{|c|c|c|}
\hline Element & Mass Gain & Mass Loss \\
\hline Co & - & -2.18 \\
Cr & - & +0.92 \\
Mo & -1.68 & - \\
W & -0.90 & -1.14 \\
Ta & +1.65 & +4.4 \\
CrCo+CW+MoTa & - & -0.90 \\
\hline
\end{tabular}

and by one or more of the two-element interactions combined in the $(\mathrm{CrCo}+\mathrm{CW}+\mathrm{MoTa})$ confused interaction effect, and is increased by the increases in $\mathrm{Ta}$ and $\mathrm{Cr}$ content.

These mass change data indicated that oxidation resistance was decreased by the increase in Ta content. Since Ta had been included in the alloys to increase solid solution strengthening, its retention at the $2 \%$ level on the basis of this initial oxidation study was clearly premature. The design of the Group B alloy compositions was, therefore, formulated by using minor additions of $\mathrm{Mn}, \mathrm{Si}$, and $\mathrm{Y}$ to improve oxidation resistance while retaining $\mathrm{Ta}$ at its former levels.

The increases in Co from $4 \%$ to $10 \%$, in Mo from $8 \%$ to $12 \%$ and in $W$ from $2 \%$ to $6 \%$ in the Group A alloys were beneficial in increasing oxidation resistance. At the same time, the phase stability aging treatment of these alloys led to the precipitation of $\mu$ phase in alloys A-3 to A-16. Therefore it was clear that lower levels of the $\mu$-forming elements should be used in the next phase of the study while retaining emphasis on elements that would provide maximum solid solution strengthening. Accordingly the lower levels of $\mathrm{Cr}$, $\mathrm{Co}$, and Mo were used in the design of Group B alloy compositions, together with the upper W level.

\section{Group B Alloys}

Oxidation Study. The mass changes observed for the Group $B$ alloys were recorded. Oxidation was protective to varying degrees for all alloys, and the mean mass gain for the alloys at any specific time was less than the mean gain at the same time for the Group A alloys. Thus the alloy modifications had achieved the desired effect of decreasing the extent of oxidation. However the degree of oxide spalling was much greater than that recorded for the Group A alloys, indicating need for further compositional modification.

Statistical analysis of the mass gain and spalled oxide data after 400 hours exposure was performed as before. The elements identified as influencing the oxidation resistance of 
Tahle 3 Croup B Coefficients for Significant Effects After Oxidation at $1095 \mathrm{C}(2000 \mathrm{~F})$ for 400 Hours

\begin{tabular}{|c|c|c|}
\hline Element & Mass Gain & Mass Loss \\
\hline $\mathrm{A} 1$ & -0.48 & -5.06 \\
$\mathrm{Mn}$ & -0.78 & -4.61 \\
$\mathrm{Si}$ & -0.50 & - \\
$\mathrm{Ta}$ & -0.65 & -3.04 \\
$\mathrm{Y}$ & -0.92 & -3.64 \\
$\mathrm{~A} 1 \mathrm{X}$ & -1.42 & -5.06 \\
$\mathrm{MnY}$ & +0.52 & -3.24 \\
\hline
\end{tabular}

\begin{tabular}{|l|c|c|}
\hline Fiement & Mass Gain & Mass Loss \\
\hline SiTa & - & +6.59 \\
SiA1 & - & +6.11 \\
SiY & +0.70 & +3.89 \\
SiMn & - & -1.91 \\
IaY & - & +3.24 \\
TaA1 & - & +1.91 \\
TaMn & - & +1.16 \\
\hline
\end{tabular}

the alloys are listed in Table 3 together with their respective coefficients. Table 3 indicates that mass gain is diminished by the specified increases in $\mathrm{Al}, \mathrm{Mn}, \mathrm{Si}, \mathrm{Ta}$, and $\mathrm{Y}$, and by a strong synergism between $\mathrm{AI}$ and $\mathrm{Y}$. Synergism between $\mathrm{Si}$ and $\mathrm{Y}$, and $\mathrm{Si}$ and $\mathrm{Ta}$, leads to increases in mass gain. Oxide spalling is decreased by the increases in $\mathrm{Al}, \mathrm{Mn}, \mathrm{Ta}$ and $\mathrm{Y}$, and by synergism between $A 1$ and $Y$, $M n$ and $Y$, and $M n$ and $S i$. Oxide spalling is increased by synergistic interactions between $\mathrm{Si}$ and $\mathrm{Y}, \mathrm{Si}$ and $\mathrm{Al}, \mathrm{Si}$ and $\mathrm{Ta}, \mathrm{Ta}$ and $\mathrm{Y}, \mathrm{Ta}$ and $\mathrm{Al}$, and $\mathrm{Ta}$ and $\mathrm{Mn}$. EvidentIy the increases in both Si and $\mathrm{Ta}$ contents in these Group $\mathrm{B}$ alloys give rise to a marked decrease in resistance to oxide spalling in the presence of both $\mathrm{Al}$ and $\mathrm{Y}$, although in isolation Ta contributes towards an increase in resistance to spalling.

The most oxidation-resistant arc-cast alloy at this stage of the study was Alloy $\mathrm{B}-12$. The scale was composed predominantly of $\mathrm{Cr}_{2} \mathrm{O}_{3}$, with $\mathrm{Y}$-rich particles extending into the matrix below the scale. The oxidation resistance of this alloy approached that of the Incone1 617 sample in this test.

The information gained on alloying effects was then combined in the design of the Group $C$ alloy compositions. The composition of Alloy B-12 was used as a guide in developing the alloy group. Low carbon levels were used to minimize the tendency for the formation of large blocky carbides during casting that could decrease LCF resistance. Both $A 1$ and $Y$ were retained and were increased to $2 \%$ and $0.2 \%$, respectively, in an attempt to gain further increases in oxidation resistance over that of the Group B alloys. Cr was maintained at 20\% and Co was increased to $8 \%$ to gain some further increase in spalling resistance. The concentrations of $\mathrm{Mo}, \mathrm{W}$, and $\mathrm{Ta}$ were chosen to provide maximum solid solution strengthening in addition to oxidation resistance, with emphasis being placed on $W$ and $T a$, the elements with larger atomic diameters. Thus Mo was varied between $4 \%$ and $8 \%$, and $W$ and Ta were each varied from $6 \%$ to $9 \%$. It was recognized that several of the more highly alloyed compositions would be unstable with respect to TCP phase precipitation. 


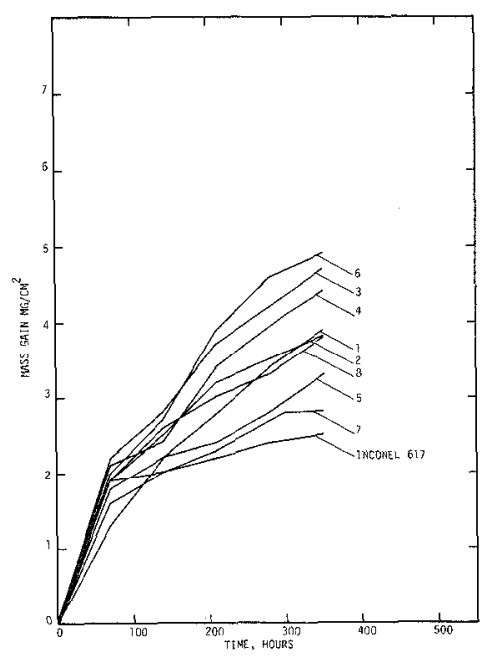

(a)

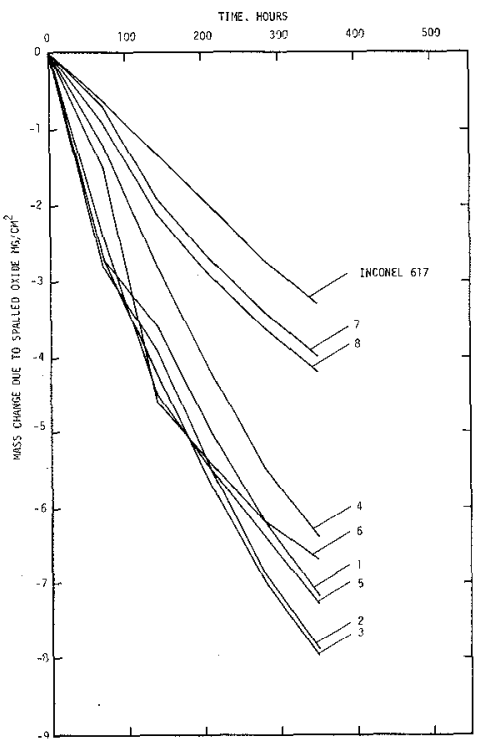

(b)

Fig. 1 Specific Mass Changes of Group C Alloys. a) Mass gain, b) Mass loss due to spalled oxide.

\section{Group C Alloys}

Oxidation Study. The mass change data for the Group C alloys are shown in Figure 1. These alloys exhibited a general improvement in oxidation resistance over that of the two previous alloy groups. A major improvement in resistance to oxide spalling was evident, with Alloys $\mathrm{C}-7$ and $\mathrm{C}-8$ exhibiting greater overall spaling resistance than Alloy B-12. Thus these two compositions approached an oplimum composilion for oxidation resistance under the laboratory test conditions. The closest approach to the oxidation resistance of Inconel 617 was exhibited by Alloy $\mathrm{C}-7$.

Statistical analysis of the mass changes data after 350 hours exposure yielded the set of coefficients listed in Table 4 for those elements that influenced the oxidation resistance of the alloys. Table 4 indicates that mass gain is diminished by the combined interaction ( $\mathrm{CTa}+\mathrm{MoW}$ ) but is increased by the increase in carbon content and by the combined interaction $(\mathrm{CW}+\mathrm{MoTa})$. Oxide spalling is decreased by the increases in Mo and $W$ and by the combined interaction (CTa + MoW). Neither 
E. P. Whetan / 59

Table 4 Group C Coefficients

\begin{tabular}{|c|c|c|}
\hline Element & Mass Gain & Mass Loss \\
\hline C & +0.55 & - \\
Mo & - & -1.62 \\
W & - & -1.82 \\
CW+MoTa & +0.75 & - \\
CTa+Mow & -0.50 & -1.28 \\
\hline
\end{tabular}

changes in Ta content from $6 \%$ to $9 \%$ nor the higher $\mathrm{Al}$ and $\mathrm{Y}$ levels appear to have influenced oxidation resistance. Alloys with the higher Mo and $W$ levels and the lower $C$ levels exhibit the best overall oxidation resistance. This observation on the contributions of Mo and $W$ to oxidation resistance is consistent with the data obtained for the Group A alloys. The contributions of each two-factor interaction to the (CW + MoTa) and $(\mathrm{CTa}+\mathrm{MoW})$ combined interaction effects recorded for the Group $C$ alloys cannot be isolated without further study. However, it may be speculated that rapid oxidation of carbides and subsequent scale spalling could account for the general detrimental effect of increased carbon on mass gain and for possible detrimental CW and CTa synergistic interaction effects, whereas synergism between Mo and $W$ could account for beneficial influences on both mass gain and oxide spalling.

After aging at $870 \mathrm{C}(1600 \mathrm{~F})$ for 700 hours, $\mathrm{M}_{6} \mathrm{C}$ carbide and $\mu$ phase were found to have precipitated in all alloys except Alloy $C-1$, in which only $M_{6} C$ had precipitated. $A 11$ alloys contained $\mathrm{M}_{23} \mathrm{C}_{6}$ and $\mathrm{MC}$ carbides.

\section{Group D Alloys}

Alloy Compositions. The oxidation and phase stability data observed in this study were synthesized in the formulation of the compositions of the Group D alloys. Co had been observed to improve oxide spalling resistance in the Group A alloys but had not prevented the achievement of good oxidation resistance in the Group B alloys when maintained at $4 \%$. The improvement in oxidation resistance of the better Group $C$ alloys, approaching equivalence to Inconel 617, was attributable at least in part to their higher Mo and $W$ contents, and the increase in Co from $4 \%$ in the Group $B$ alloys to $8 \%$ in the Group $C$ alloys was apparently not associated with an obvious improvement in oxidation resistance. Thus the lower Co content A1loy $\mathrm{B}-12$ (4Co, $8 \mathrm{Mo}, 6 \mathrm{~W}, 6 \mathrm{Ta}$ ) exhibited a slight1y lower mass gain and an equivalent mass of spalled oxide when compared with the higher co content Alloy $\mathrm{C}-4$ ( $8 \mathrm{Co}, 8 \mathrm{Mo}, 6 \mathrm{~W}, 6 \mathrm{Ta})$. Therefore, in the absence of a clearly defined, unique, beneficial contribution 
to oxidation resistance from $\mathrm{Co}$, this element was not included in the Group D alloys. High and low levels of Mo and $W$ were examined. Ta was retained at a low level because, although it would contribute to solid solution strengthening, it would also contribute to phase instability, and the absence of a strong contribution to oxidation resistance did not justify a high content. As anticipated, Alloy D-1 was unstable with respect to $\mu$ phase formation whereas Alloy $D-2$ was stable.

Stress Rupture Properties. Stress rupture tests were made on sheet samples of Alloys $D-1$ and $D-2$ following solution treatment. Table 5 shows rupture data for tests betwcen $870 \mathrm{C}$ $(1600 \mathrm{~F})$ and $1095 \mathrm{C}(2000 \mathrm{~F})$ for the indicated solution treatment. High solution temperatures were required in order to achieve grain sizes in the range ASTM No. 2-4 in the hot rolled sheet. The data for Alloy D-2 are displayed in the LarsonMiller curve of Figure 3 where they are contrasted with pubIished data for commercial Inconel 617 (4) and Haynes Alloy 188 (5). The rupture properties of $\Lambda 110 y \mathrm{D}-2$ at $870 \mathrm{C}(1600 \mathrm{~F})$ and $1095 \mathrm{C}(2000 \mathrm{~F})$ approach closely the rupture properties of the commercial alloys. This similarity in properties indicates that the addition of Co is not essential to the achievement of an acceptable high temperature rupture life in this alloy. The rupture specimens tested at $980 \mathrm{C}(1800 \mathrm{~F})$ failed prematurely due to excessive grain boundary oxidation, believed to be associated with reduced oxidation resistance of the alloy due to its low $\mathrm{Y}$ content.

Table 5 Stress Rupture Data for Group D Alloys

\begin{tabular}{|c|c|c|c|c|c|c|c|c|}
\hline \multirow{2}{*}{ Alloy } & \multicolumn{2}{|c|}{$\begin{array}{l}\text { Solution } \\
\text { Treatment, }\end{array}$} & \multicolumn{2}{|c|}{$\begin{array}{c}\text { Test } \\
\text { Temperature, }\end{array}$} & \multicolumn{2}{|r|}{ ess } & \multirow{2}{*}{$\begin{array}{l}\text { Rupture } \\
\text { Life, Hr }\end{array}$} & \multirow{2}{*}{$\underset{\%}{E 1 .}$} \\
\hline & & (15) & & & MEa & $(15)$ & & \\
\hline \multirow[t]{2}{*}{$D-1$} & 1260 & $(2300) / 1$ & 1095 & $(2000)$ & 21 & (3) & 37.5 & 51 \\
\hline & 1230 & $(2250) / 4$ & 1095 & $(2000)$ & 21 & (3) & 55.1 & 40 \\
\hline $\mathrm{D}-2$ & 1260 & $(2300) / 1$ & $\begin{array}{r}1095 \\
980 \\
870\end{array}$ & $\begin{array}{l}(2000) \\
(1800) \\
(1600)\end{array}$ & $\begin{array}{r}21 \\
48 \\
117\end{array}$ & $\begin{array}{r}(3) \\
(7) \\
(17)\end{array}$ & $\begin{array}{r}41.7 \\
9.5 \\
45.6\end{array}$ & $\begin{array}{l}48 \\
39 \\
14\end{array}$ \\
\hline & 1205 & $(2200) / 1$ & $\begin{array}{r}1095 \\
1095 \\
980 \\
980 \\
870 \\
870\end{array}$ & $\begin{array}{l}(2000) \\
(2000) \\
(1800) \\
(1800) \\
(1600) \\
(1600)\end{array}$ & $\begin{array}{r}21 \\
21 \\
48 \\
48 \\
117 \\
117\end{array}$ & $\begin{array}{r}(3) \\
(3) \\
(7) \\
(7) \\
(17) \\
(17)\end{array}$ & $\begin{array}{r}38.2 \\
26.6 \\
9.1 \\
8.0 \\
68.6 \\
44.8\end{array}$ & $\begin{array}{l}70 \\
62 \\
44 \\
40 \\
20 \\
15\end{array}$ \\
\hline
\end{tabular}




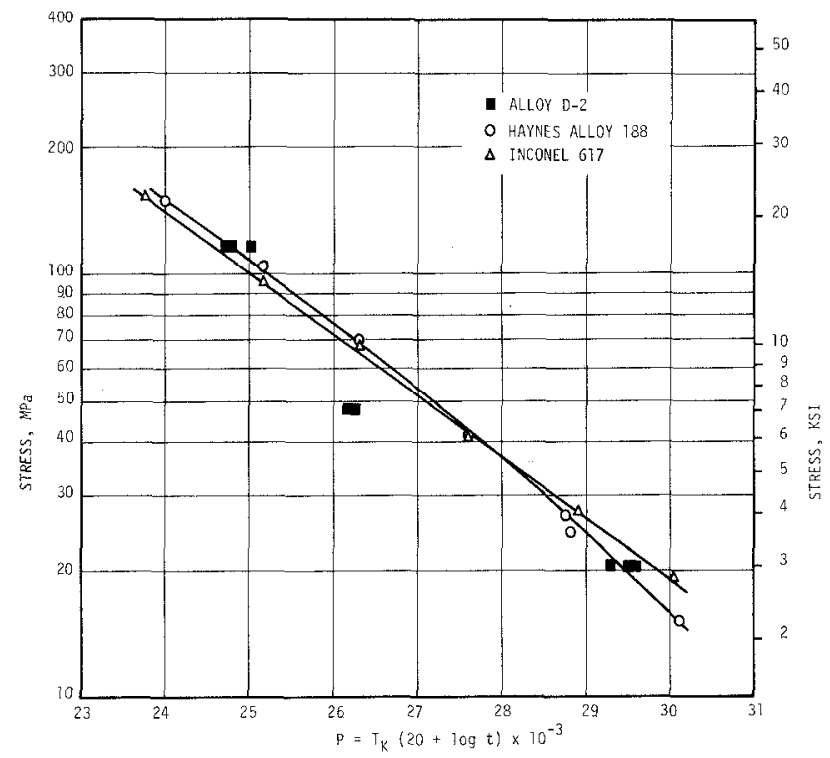

Fig. 3 Larson-Miller Parameter P1ot for Rupture Lives of Alloy D-2, Inconel 617 and Haynes Alloy 188.

\section{CONCLUSIONS}

It is clear from this work that cobalt-free nickel-base superalloys with high temperature oxidation resistance and stress rupture properties approaching those of cobaltcontaining commercial high temperature alloys can be developed. The presence of significant concentrations of Mo and $W$ is re-quired in these Co-free alloys for the achievement of adequate high temperature properties.

\section{ACKNOWLEDGEMENT}

The technical assistance of M. A. Zeoli and discussions with W. C. Hagel and D. L. Sponseller are appreciated. 


\section{REFERENCES}

1. R. B. Herchenroder, S. J. Matthews, J. W. Takett and S. T. Wlodek, "Haynes Alloy No. 188," Cobalt, Vol. 54, 1972, p. 3.

2. W. L. Mankins, J. C. Hosier and T. H. Bassford, "Microstructure and Phase Stability of Inconel Alloy 617, Met. Trans. Vo1. 5, 1974, p. 2579.

3. 0 . L. Davies (Ed.), "The Design and Analysis of Industrial Experiments," Hafner Publishing Co., N.Y., 1973, p. 263.

4. "Incone1 617" in "Alloy Digest," Engineering Alloys Digest, Inc., N.J. Filing Code: Ni-179, Sept. 1972.

5. "Haynes Alloy No. 188" in "Alloy Digest," Engineering Alloys Digest, Inc., N.J. Filing Code: Co-62, January 1971. 